\title{
STRESSOR AND COPING STRATEGIES OF PEOPLE LIVING WITH HIV/AIDS (PLWHA): A LITERATURE REVIEW
}

\author{
Ahmad Ikhlasul Amal ${ }^{1}$, Moses Glorino Rumambo Pandin ${ }^{2}$ \\ ${ }^{1}$ Doctoral Nursing Student of Universitas Airlangga, ahmad.ikhlasul.amal-2020@fkp.unair.ac.id \\ ${ }^{2}$ Lecturer at Faculty of Culture Universitas Airlangga, moses.glorino@ fib.unair.ac.id
}

Correspondence Author: Ahmad Ikhlasul Amal, ahmad.ikhlasul.amal-2020@fkp.unair.ac.id, Doctoral Nursing Student, Universitas Airlangga, Soekarno Street, Mulyorejo, Surabaya City, East Java, Indonesia.

\begin{abstract}
Background: A person living with HIV / AIDS bargains with stressors such as discrimination, stigma depression, and several psychological impacts. The stressors experienced by people with HIV/ AIDS will certainly have an impact on daily activities, welfare, and management of medications which in general will have an impact on the quality of life. To deal with these stressors, it is necessary to have good and proper coping from within the PLWHA. Coping strategies need to be owned and carried out by PLWHA in order to respond adaptively to the stressor conditions experienced. Purpose: The aim of this review is to describe the stress experienced and the coping strategies used among PLWHA. Methods: This literature review used keywords in the search for international references are coping strategy, stressor, HIV-AIDS. Inclusion criteria: selection of titles that are relevant to the formulation of the problem and objectives, full-text articles in English, articles published from 2019 to 2021. The exclusion criteria used were coping strategy articles that did not involve HIV patients. Search references from electronic database sources namely ProQuest, CINAHL, and ScienceDirect.Six articles that are deemed worthy of analysis are then discussed or analyzed. Results: Age, gender and sexual orientation have contributed to the emerging stressor among PLWHA. The internal and external coping strategies focusing on the problem are important for PLWHA in handling the stressor. Conclusion: People with HIV-AIDS have many stressors in their lives, but they also have proper coping strategies depending on their internal and external conditions.
\end{abstract}

Keywords: Stressor, Coping Strategies, HIV/AIDS

\section{INTRODUCTION}

Misinformation and perception related to HIV/AIDS cause the public to view the sufferer as a negative person. This negative assessment can lead to an assessment of stigma and discrimination, which is often a predisposing factor for the causes of stressors reporting PLWHA(1).

A person living with HIV / AIDS bargains with stressors such as discrimination, stigma depression, and several psychological impacts. The stressors experienced by people with HIV/ AIDS will certainly have an impact on daily activities, welfare, management of medications which in general will have an impact on the quality of life(2). Quality of life is a major component in evaluating the psychological well-being of PLWHA. This is because the quality of life can reflect the value system of goals, standards, and expectations of a person and the absence of functional difficulties in carrying out daily activities. $(3,4)$.

Data shown by UNAIDS (2020) shows that 1.7 million people were living with HIV in 2019 and around 690 million people died from AIDS in the same year. Of the 25 countries for which data related to discrimination in this disease was collected, it was found that there were still over $50 \%$ of HIV sufferers experiencing discrimination. In Indonesia alone, there are 330,000 confirmed cases of HIV incidence and around $62.6 \%$ of people in Indonesia still behave discriminatively against PLWHA(5)(6,7).

A stressor is felt to provide an advantage when in a minimum dose and amount, this can increase motivation and excitement. The statement will be inversely proportional if the stressor is not properly managed, mistakes and the inability to resolve 
the stressor can increase the risk or danger to the health and well-being of an individual $(8,9)$.

People with HIV-AIDS also experience psychosocial problems. Psychosocial problems in some people with HIV/AIDS can trigger stressors. This results in the inability of HIV-AIDS sufferers to reach health services and support that are already available so that it has an impact on the physiology and emotion of HIV sufferers $(1,10)$.

The complexity of the problems experienced by HIV-positive sufferers may have an effect on decreasing quality of life. PLWHA tend to choose to use maladaptive coping mechanisms in solving the problems they face. Of course, this will certainly worsen the condition of the patient's body $(3,11)$.

To deal with these stressors, it is necessary to have good and proper coping from within the PLWHA. Coping strategies need to be owned and carried out by PLWHA in order to respond adaptively to the stressor conditions experienced(12).

There are two focuses on coping strategies proposed by Lazarus and Folkman 1984, namely, focus on problems and focus on emotions. Stroppa 2008 added a new coping strategy, namely religious/spiritual coping. Focus on the problem means direct action taken to solve the problem. The focus of problem-solving includes confrontative coping, planful problem solving and seeking social support. Focusing on emotions means an effort to address emotional function modification without trying to change the problem directly. This focus includes a positive response, accepting responsibility, self-controlling, distancing, and escape avoidance. A spiritual-focused coping strategy is an individual's way of believing that he can cope with life's stresses and problems. Pargament said that spiritual coping is closely related to the relationship between humans and the creator when experiencing problems (13).

The aim of this review is to describe the stressor experienced and the coping strategies used in people with HIV/AIDS.

\section{METHOD}

This literature review uses the narrative conceptual synthesis method. The steps carried out in this literature review are as follows: 1) Formulation of the problem. What is the coping strategy in HIV-AIDS patients who experience stressors? Keywords in the search for international references are coping strategy, stressor, HIV-AIDS. 2) Inclusion criteria: selection of titles that are relevant to the formulation of the problem and objectives, full-text articles in English, articles published from 2019 to 2021. The exclusion criteria used were coping strategy articles that did not involve HIV patients. 3) Search references from electronic database sources namely ProQuest (136 articles), CINAHL (89 articles) and ScienceDirect (62 articles). 4) Six articles that are deemed worthy of analysis are then discussed or analyzed.

\section{RESULTS}

Research from Emmanuel (2019) with the aim of identifying coping strategies as a predictor of the quality of life of PLWHA with a cross-sectional design model in 200 samples found that quality of life was influenced by the coping strategies used. Furthermore, the researcher said that the environmental aspect of the quality of life is the domain that has the highest value, while the spiritual aspect is the lowest. Coping strategies give a valuable role in determining quality of life of PLWHA. The researcher also presents that the coping strategies used are , active coping, distraction, denial, emotion use, planning, instrument support, venting, behavior disengagement, positive reframing, humor, slpiritual/religion and self-blame(3).

A cross-sectional study established by O.H. Ezeh Ahmadu Bello University Teaching Hospital (ABUTH), Zaria, Nigeria, found that Overall more than 60 percent of HIV patients tested positive for one dysfunctional coping dimension or another. The results showed different prevalence rates on the four main domains of dysfunctional coping come from the Brief-cope questionnaire, used to assess 
dysfunctional coping are in this study. The analysis revealed a correlation between rejection of coping and duration of HIV infection/survival. The emergence of dysfunctional coping is quite common among HIV patients. Dysfunctional management may be a determinant of health in HIV patients and significantly affect health outcomes. Therefore, it is suggested that some interventions focus on coping strategies be integrated to the treatment among HIV patients, in order to increase their physical and psychological well-being(14).

Meanwhile, another cross-sectional research established at Jugal Hospital, Eastern Ethiopia, showed that women confimed a higher stigma of disclosing HIV status rather than men and coping strategies types used differed between men and women. The overall result by Berger stigma scale perceived stigma score means did not differ statistically within men and women. Among the four subscales, women confirmed a higher level of disclosure stigma than men $(21.1 \pm 5.5$ vs $20.3 \pm 5.5 ; \mathrm{p}=$ 0.006). Concerning maladaptive coping strategies, men used the substance more frequently than women. However, women used behavioral disengagement and selfdistraction more frequently than men. Women used a higher level of adaptive coping strategies than men. Furthermore, woman were found to use coping that focused more on emotion than males. The conclusion obtained from this study is that treatments to assist PLWHA must come into gender differences in relation to perceived stigma(15)

Research conducted by Sabina and colleagues in Nepal found that the correlation of perceived social support with quality of life was significant and partly mediated by problem-focused coping strategies. The stigma internalized in PLWHA significantly moderates the mediating impact of coping strategies on the relationship of perceived social support with quality of life.. Internal stigma was found to moderate the effect of mediation in overcoming problems that focus on the correlation between social supports with quality of life. Increasing problemfocused coping as well as the presence of social support may be useful for improving the quality of life among PLWHA who report high stigma(16)

In the study of stigma and discrimination as well as coping strategies carried out in the city of Medan, North Sumatra, 4 coping themes were obtained, namely 1) Have experienced stigma and discrimination from health workers, 2) Have experienced psychological impacts, 3) Continue to continue treatment to health services, 4) Expectations on health services. Furthermore, it was concluded that PLWHA in the city of Medan still have positive coping in facing stigma and discrimination so they can continue to receive treatment in health services(1).

A study in China examined the relationship between perceived and internalized stigma, positive coping, perceived stress, and quality of life in PLWHA. Perceived and internalized stigma has a direct negative impact on Quality of Life. In addition, perceived and internalized stigma has an indirect effect on the quality of life through alleviated positive coping and improved perceived stress. Multilevel managements to decrease perceived and internalized stigma and stress, as well as perceived stress due to programs to increase positive coping, can improve the quality of life of PLWHA. Integrated interventions that both increase positive coping and reduce stress and perceived stigma have the potential to be more efficacious in improving quality of life than programs that focus only on one aspect of stigma decrement among PLWHA. These results indicate that coping and positive perceptions of stress indirectly affect the correlation between acceptance and internalization of stigma and quality of life. The findings suggest that multilevel managements focused at reducing stigma, perceptions of perceived and internalized stress and increasing positive coping can improve the quality of life of PLWHA. Integrated managements that increase adaptive coping and decrease perceived stress and stigma are posible more potential than 
programs that focus on reduction of stigma (17).

\section{DISCUSSION}

Coping strategies are strategies that individuals use to deal with accepted changes. If the coping strategy is successful, then that person will be able to adapt to the changes they experience. Coping strategies can be applied, from the very beginning of the stressor and people are aware of the impact of these stressors. The results of a literature review conducted in six articles, it can be found that a number of coping strategies are implemented, especially in the case of PLWHA. HIV sufferers generally experience pressure or stress both from within (stress and depression) and from without (stigma and discrimination) to their illness. A number of issues related to coping strategies include age, sex, and sexual orientation, dysfunctional coping (negative coping), as well as various coping techniques and domains that are implemented(18)(19).

The age of PLWHA has an influence on the choice of coping strategies, where young PLWHA tend to have problems in communicating with their caregivers (both doctors and nurses) and regularity in anti-viral drug therapy, so a special ping strategy is needed(12). Meanwhile, it is easier for PLWHA to manage coping strategies. Older adults tended to be more convinced and more prone to adher on treatment, to feel respected and also welcomed by these people. However, because they are aware of discrimination and prejudice against individuals with HIV, sensitive older adults sometimes tend to utilize furtiveness as other form of coping method, which is represented in their will to accept and protect themselves(20)(21).

Gender differences also affect coping styles and methods. Women used prominently emotional-based coping strategies than men. The findings with respect to gender differences in dealing with HIV stressor, ranging from studies that highlight gender differences less, to studies pointing to higher rates of self-isolation, spiritual approaches, and social support as coping strategies in HIVinfected women. Male PLWHA more than female sufferer to utilize illegal substances as their coping. This is congruous with the finding that male patients are more likely to engage in risky behavior than women. Women show higher rates of adaptive coping than men. Where women are more feasibly to utilze adaptive coping strategies such as planning or religious practice (15).

In risk groups, such as homosexuals, there are several coping strategies that can be applied depending on social conditions and beliefs towards religion, such as support peer community, the return of their lives to religious teachings (repentance), and support from people close to them (22).

Wrong coping mechanisms or dysfunctional coping or negative coping is one of the issues that often occur in PLWHA. Examples of dysfunctional coping include neglect of anxiety, stress, substance use, running away from medication, etc. Management of dysfunctional coping can be a conclusive of health of PLWHA and importantly affect their health outcomes. Therefore, it is suggested that managements be made on coping strategies that are integrated into HIV patient care intervention to improve the psychological and physical health of PLWHA. (14,23). Conversely, positive coping indirectly has a good impact on reducing stress levels and the quality of life of PLWHA (17)

Studies of active coping strategies in all 4 domains of Quality of Live (physical, emotional, spiritual, and social) and exacerbating behavioral release generally show good results. The physical domain has a significant positive correlation with active coping, ventilation, emotional support, planning, positive framing, and religion. Letting go of behavior and blaming yourself has a negative impact, indicating that someone is positive. The mindset and planning of activities together with emotional support can improve the quality of the physical aspect. Along with active coping, emotional and religious support also increased psychological status, while substance abuse, behavioral 
abandonment, and self-blame decreased the domain scores significantly. Researchers found that emotional support improved psychological health. Spirituality reflects positive emotions and enhances life quality. Commitment in religion plays a role in improving disease prevention, overcoming disease, and recovery. Active coping, emotional support, positive framing, instrumental support, and humor make the social aspect of the subject better. The domain of the social environment in those who are active and have positive attitude framing. This suggests that active people can get the most out of the facilities available. On the other hand, the release of behavior and substance abuse can abstain from coping, by utilizing the resources and facilities provided for PLWHA $(21,24,25)$.

A coping strategy that focuses on problems, can partially mediate the associaton between perceived social supports with quality of life among PLWHA. Furthermore, this mediation effect varies depending on the level of internalized stigma. Perceived social support from family, friends, and loved ones, as well as problem-focused coping strategies, should be increased among PLWHA to increase quality of life, especially important for those who report high levels. (16)

Factors related to coping strategies in facing various stresses internally and externally, PLWHA is expected to maintain positive coping in facing these challenges. Nurses, healthcare providers and citizens are expected not to stigmatize and discriminate for PLWHA, considering that this has an impact on HIV/AIDS treatment and prevention programs $(1,26)$.

\section{CONCLUSION}

People with HIV-AIDS have many stressors in their lives. The stress experienced by PLWHA can come from various sources, but the majority is due to stigma and discrimination. The coping strategy carried out by PLWHA varies depending on its internal and external conditions. Coping strategies need to be implemented to achieve a good quality of life while suffering from HIV / AIDS.

\section{CONFLICT OF INTEREST}

There is no conflict of interest in this review literature study.

\section{REFERENCES}

1. Hasibuan EK, Aryani N, Simanjuntak GV. Stigma dan diskriminasi serta strategi koping pada orang dengan HIV dan AIDS (ODHA) di kota Medan, Sumatera Utara. Holistik J Kesehat. 2020;13(4):396-401.

2. Krisdayanti E, Hutasoit JI. Pengaruh Coping Strategies terhadap Kesehatan Mental dan Kualitas Hidup Penderita HIV/AIDS positif. J Ilmu Keperawatan Jiwa. 2019;2(3):179.

3. OSAMIKA BE. Coping Strategies Predicting Quality of Life Among People Living With Hiv/Aids. PEOPLE Int J Soc Sci. 2019;4(3):1689-711.

4. English K, May SB, Davila JA, Cully JA, Dindo L, Amico KR, et al. Retention in Care and Viral Load Improvement After Discharge Among Hospitalized Out-of-Care People With HIV Infection: A Post Hoc Analysis of a Randomized Controlled Trial. Open Forum Infect Dis. 2020;7(6):1-10.

5. UNAIDS. DATA. 2020.

6. UNAIDS. living with HIV Coverage of adult [Internet]. 2019. 1-10 p. Available from: https://www.unaids.org/en/regionscount ries/countries/indonesia

7. Katana P V., Abubakar A, Nyongesa MK, Ssewanyana D, Mwangi P, Newton CR, et al. Economic burden and mental health of primary caregivers of perinatally HIV infected adolescents from Kilifi, Kenya. BMC Public Health. 2020;20(1):1-9.

8. Umucu E, Lee B. Examining the impact of COVID-19 on stress and coping strategies in individuals with disabilities and chronic conditions. Rehabil 
Psychol. 2020;65(3):193-8.

9. Revenson TA, DeLongis A. Couples Coping with Chronic Illness. Oxford Handb Stress Heal Coping. 2012;2.

10. de los Rios P, Okoli C, Castellanos E, Allan B, Young B, Brough G, et al. Physical, Emotional, and Psychosocial Challenges Associated with Daily Dosing of HIV Medications and Their Impact on Indicators of Quality of Life: Findings from the Positive Perspectives Study. AIDS Behav [Internet]. 2021;25(3):961-72. Available from: https://doi.org/10.1007/s10461-02003055-1

11. Chan RCH, Operario D, Mak WWS. Effects of HIV-related discrimination on psychosocial syndemics and sexual risk behavior among people living with HIV. Int J Environ Res Public Health. 2020;17(6).

12. Sabin LL, Nguyen VC, Harvey K, Bonawitz R, Hai LT, Van Lam N, et al. Challenges to Antiretroviral Therapy Adherence and Coping Strategies to Overcome Them: Qualitative Investigations of Adolescents Living with HIV, their Caregivers, and Clinicians in Vietnam. Open AIDS J. 2020;14(1):114-26.

13. Rohman R, Nursalam N, Sukartini T, Imansyah $\mathrm{R}$. The relationship between spiritual meaning of the experience of illness and the use of coping strategies in people living with HIV/AIDS. Int J Psychosoc Rehabil. 2020;24(7):781724.

14. Ezeh OH. Diagnosing Dysfunctional Coping in HIV-Infected Persons. Open J Med Psychol. 2019;08(02):36-43.

15. Ataro Z, Mengesha MM, Abrham A, Digaffe T. Gender differences in perceived stigma and coping strategies among people living with hiv/ aids at jugal hospital, harar, ethiopia. Psychol Res Behav Manag. 2020;13:1191-200.

16. Subramanian A, Mohan A, Nandi PK, Rajeshwari K. Perceived social support, depression and their impact on quality of life of people living with HIV in
India. AIDS Care - Psychol SocioMedical Asp AIDS/HIV. 2020;31(4):413-20.

17. Zhu M, Guo Y, Li Y, Zeng C, Qiao J, $\mathrm{Xu} \mathrm{Z}$, et al. HIV-related stigma and quality of life in people living with HIV and depressive symptoms: indirect effects of positive coping and perceived stress. AIDS Care - Psychol SocioMedical Asp AIDS/HIV [Internet]. 2020;32(8):1030-5. Available from: https://doi.org/10.1080/09540121.2020. 1752890

18. Brown MJ, Serovich JM, Laschober TC, Kimberly JA, Lescano CM. Ways of coping and HIV disclosure among people living with HIV: mediation of decision self-efficacy and moderation by sex. AIDS Care - Psychol SocioMedical Asp AIDS/HIV. 2019;31(8):1001-10.

19. Jones DL, Ballivian J, Rodriguez VJ, Uribe C, Cecchini D, Salazar AS, et al. Mental health, coping, and social support among people living with HIV in the Americas: A comparative study between Argentina and the USA during the SARS-CoV-2 pandemic. Res Sq [Internet]. 2020;1-13. Available from: http://www.ncbi.nlm.nih.gov/pubmed/3 3236005\%0Ahttp://www.pubmedcentra 1.nih.gov/articlerender.fcgi?artid=PMC 7685328

20. Garrido-Hernansaiz H, Alonso-Tapia J, Martín-Fernández M. Coping in newly diagnosed, Spanish-speaking men who have sex with men and live with HIV** a Bayesian approach. Eur J Ment Heal. 2019;14(1):41-57.

21. Folayan MO, Cáceres CF, Sam-Agudu NA, Odetoyinbo M, Stockman JK, Harrison A. Psychological Stressors and Coping Strategies Used by Adolescents Living with and Not Living with Hiv Infection in Nigeria. AIDS Behav. 2017;21(9):2736-45.

22. Adia AC, Ng MJ, Quilantang MI, Restar AJ, Hernandez LI, Imperial RH, et al. Collective coping strategies for HIV-related challenges among men 
who have sex with men in Manila, Philippines. AIDS Educ Prev. 2019;31(5):479-90.

23. Fauk NK, Merry MS, Mwanri L. Meaning-making as a coping strategy among transgender women living with HIV in Indonesia. AIDS Care - Psychol Socio-Medical Asp AIDS/HIV [Internet]. 2021;33(2):167-71. Available from: https://doi.org/10.1080/09540121.2020. 1716934

24. Negi T, Zama SY, P. D. Quality of life in HIV patients and coping strategies adopted by them: a cross sectional study done in an anti-retroviral therapy centre, Mysore. Int J Community Med Public Heal. 2019;6(8):3326.

25. de Melo Brandão BMG, de Moura
Angelim RC, Marques SC, de Oliveira RC, da Silva Abrão FM. Living with HIV: Coping strategies of seropositive older adults. Rev da Esc Enferm. 2020;54:1-8.

26. Chen D, Duan L, Chen X, Zhang Q, Chen Y, Yuan Z, et al. Coping strategies and associated factors among older Chinese people living with HIV/AIDS. Psychol Heal Med [Internet]. 2020;25(7):898-907. Available from: https://doi.org/10.1080/13548506.2019. 1659983 